\title{
Exploring the Function of Alcohol Dehydrogenases During the Endophytic Life of Azoarcus Sp. Strain BH72
}

\author{
Andrea Krause, Birte Bischoff, Lucie Miché, Federico Battistoni, and Barbara Reinhold-Hurek \\ Department of Microbe-Plant Interactions, University of Bremen, FB2, P.O. Box 330440, 28334 Bremen, Germany
}

Submitted 30 May 2011. Accepted 4 August 2011.

The endophytic bacterium Azoarcus sp. strain BH72 is capable of colonizing the interior of rice roots, where it finds suitable physicochemical properties for multiplying and fixing nitrogen. Because these properties are poorly understood, a microtiter-plate-based screening of a transcriptional $g f \boldsymbol{p}$ (green fluorescent protein) fusion library of Azoarcus sp. grown under different conditions was performed. Monitoring of the GFP activity allowed the identification of a gene highly expressed in medium supplemented with ethanol. Sequence analysis revealed that this gene encodes a pyrrolo-quinoline quinone-dependent alcohol dehydrogenase (ADH). Inspection of the complete genome sequence of the Azoarcus sp. strain BH72 identified seven additional genes encoding putative $A D H$, indicating that $\mathrm{BH} 72$ is well equipped to survive in different environmental conditions offering various alcohols as carbon source. Analyses of these eight putative ADH showed that expression of three was induced by ethanol, of which two were also expressed inside rice roots. The fact that waterlogged plants such as rice accumulate ethanol suggests that ethanol occurs in sufficiently high concentration within the root to induce expression of bacterial ADH. Disruption of these two ADH evoked a reduced competitiveness to the wild type in colonizing rice roots internally. Thus, it is likely that ethanol is an important carbon source for the endophytic life of Azoarcus sp.

The nitrogen-fixing bacterium Azoarcus sp. strain BH72 is a diazotrophic endophyte isolated from roots of Kallar grass (Leptochloa fusca L. Kunth) (Reinhold et al. 1986), a grass highly tolerant to waterlogging and salinity often used in Pakistan as the primary colonizer of salt-affected lands. Additionally, Azoarcus sp. is capable of colonizing rice roots under laboratory conditions in a gnotobiotic system (Hurek et al. 1994). Endophytic colonization of roots by Azoarcus sp. takes place actively. Entry sites are the zone of elongation above the root tip where the cells are still undifferentiated or the emergence points of lateral roots (Reinhold-Hurek and Hurek

Corresponding author: A. Krause; E-mail: akrause@uni-bremen.de

Current address for L. Miché: Institut Méditerranéen d'Ecologie et de Paléoécologie (UMR CNRS 6116), Ecologie microbienne et biotechnologies. Faculté des Sciences et Techniques de St Jérôme, Av. Escadrille Normandie-Niemen-Boite 441, 13397 Marseille Cedex 20, France.

Current address for F. Battistoni: Department of Microbial Biochemistry and Genomics, Instituto de Investigaciones Biológicas "Clemente Estable", Av. Italia 3318, Montevideo 11600, Uruguay.

* The $\boldsymbol{e}$-Xtra logo stands for "electronic extra" and indicates that one supplementary table is published online.
1998). Inside plants, Azoarcus sp. is observed mainly apoplastically. Colonized tissues are the outer cell layers and the root cortex, especially the aerenchyma, the main colonization site. Even the central part of roots can be invaded, from where BH72 may spread into the vegetative body of the plant (Hurek et al. 1994). Although root cells are densely colonized, no symptoms of plant disease are visible, and very limited jasmonic acid-induced defense responses are apparent (Miché et al. 2006).

Although the Azoarcus genome sequence is available (Krause et al. 2006), little is known about the genetic requirements important for the active colonization of roots. Thus far, only three determinants were identified: the type IV pili, which are important for the initial interaction with the root (Dörr et al. 1998); and the endoglucanase EglA and the PilT-mediated twitching motility, which both contribute to the invasion of the root interior (Böhm et al. 2007; Reinhold-Hurek et al. 2006).

Although Azoarcus sp. depends on a strictly respiratory metabolism, the genome carries all genetic information necessary for performing biological nitrogen fixation (Krause et al. 2006), a process requesting high energy supply and low concentration of oxygen and combined nitrogen. High nitrogenase gene expression, the key enzyme for $\mathrm{N}_{2}$ fixation, was shown to occur at the entry points of colonization plus deep inside in the intercellular space of the cortex (Egener et al. 1998, 1999). This expression pattern indicates that Azoarcus sp. finds a suitable environment for reducing atmospheric nitrogen within the plant, most probably supported by apoplastic nutrients (Egener et al. 1999; Reinhold-Hurek and Hurek 1998). Because of the high nitrogenase gene expression, this nutrient pool must be considerable; however, the composition of this pool in grasses is unknown.

Physiological experiments (Reinhold-Hurek et al. 1993a,b) and the Azoarcus genome sequence (Krause et al. 2006) revealed that the bacterium is unable to metabolize common carbohydrates and cell wall constituents, compounds expected to be present in the apoplast. This raises the question of which carbon sources this Azoarcus sp. can access in order to perform their energy-demanding, nitrogen-fixing endophytic lifestyle. Here, we describe an experimental approach to apply bacterial promoter fusions for probing the root interior for putative carbon sources, which lead to the identification of alcohol as an important carbon source for Azoarcus sp. in planta.

\section{RESULTS}

Green fluorescent protein-based screening for substrate- and plant-upregulated Azoarcus genes.

The experimental approach to probe the apoplastic nutrient pool of rice roots was based on the identification of Azoarcus genes specifically expressed in response to the availability of carbon substrates possibly present in the apoplast. Identifica- 
tion was performed by a promoter-trapping strategy which selects for promoters driving expression of marker genes under certain conditions (Cowie et al. 2006), based on the construction of a transcriptional fusion library to $g f p$ - $g u s A$ encoding green fluorescent protein and $\beta$-glucuronidase in Azoarcus sp. Briefly, the construction included ligation of random chromosomal DNA fragments into the vector pIMGG carrying the promoterless reporter genes $g f p$ and $g u s A$ (Fig. 1), followed by conjugation of the plasmid library into wild-type Azoarcus sp. strain BH72. After selection on the vector-encoded kanamycin-resistant $\left(\mathrm{Km}^{\mathrm{r}}\right)$ marker, $1.2 \times 10^{3}$ homologous recombinants were obtained. Integration of the recombinant plasmids into the genome of Azoarcus circumvents the problem that a plasmidic fusion library counts on the presence of a promoter in the cloned DNA fragment and might disturb regulatory circuits due to copy number effects. The recombinants were thereafter subjected to a microtiter-plate based GFP screening. For this, the recombinants were transferred in parallel to microtiter plates containing media supplemented with 52 different carbon sources (Supplementary Table S1), which can be either utilized by strain BH72 for growth or which are common metabolites. Expression of the marker gene $g f p$ was monitored after $4 \mathrm{~h}$ of cultivation by scanning for GFP fluorescence, which was subsequently normalized against the cell density and compared with the green fluorescence of cells incubated in carbonfree medium. Detection of green fluorescence was an indicator of induced gene expression and, therefore, represented candidate promoters for probing the apoplastic nutrient pool.

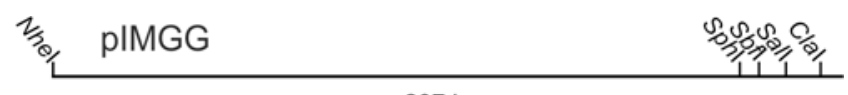

207 bps

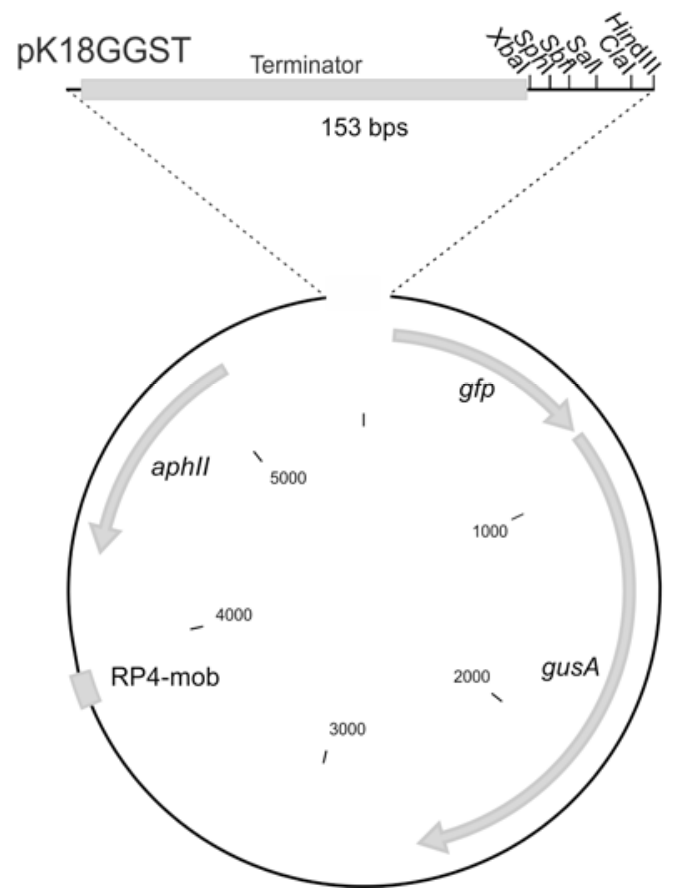

Fig. 1. Schematic map of the vectors pIMGG and pK18GGST. A cartridge containing, in tandem, the promoterless reporter genes $g f p$ and gusA, both carrying upstream of the open reading frame stop codons in all three reading frames and a Shine-Dalgarno sequence commonly used in BH72 (Egener et al. 1998, 1999), was cloned into the SalI-SmaI sites of the mobilizable suicide vector pK12mob2 (Kirchner and Tauch 2003) generating pIMGG with a multiple cloning site upstream of $g f p$ for inserting DNA fragments. By replacing the NheI-SphI fragment through a SpeI-SphI fragment carrying the T4 transcription-termination sequence of $\mathrm{pH} 45 \Omega$ (Prentki and Krisch 1984) and an additional unique XbaI site, vector pK18GGST was created.
Highest fluorescence was observed with one recombinant when ethanol was added to the growth medium, one of the major carbon sources for strain BH72 (Reinhold-Hurek et al. 2005). This observation was reevaluated by monitoring the second reporter protein, GusA, in $\beta$-glucuronidase (GUS) activity assays. The results showed an induction of expression of at least seven times when cultures were grown with ethanol compared with those cultivated in malate, a second major carbon source for Azoarcus spp. (Reinhold-Hurek et al. 1993b). The sequence of the $g f p$ flanking region of the corresponding pIMGG clone was obtained and used for a search against the Azoarcus genome (Krause et al. 2006) and protein database. The identified gene was annotated as exaA3, a gene encoding a pyrrolo-quinoline quinone (PQQ)-dependent alcohol dehydrogenase $(\mathrm{ADH})$ which is in good agreement with the induction of gene expression by ethanol.

\section{Genome-wide identification of genes encoding ADH.}

The Azoarcus genome sequence showed that, in addition to exaA3, four additional genes encode proteins with high similarity to PQQ-dependent ADH (ExaA1, ExaA2, ExaA4, and ExaA5) (Krause et al. 2006). All five predicted proteins contain structural characteristics of PQQ-dependent ADH: the conserved amino acid residues involved in PQQ binding, the eight so-called $\mathrm{W}$ motifs of the anti-parallel $\beta$-sheets (Toyama et al. 2004), and an $\mathrm{N}$-terminal signal peptide indicating a periplasmic localization known for these ADH.

On the basis of their molecular and catalytic properties, the PQQ-dependent ADH have been classified into three types (Toyama et al. 2004). In Azoarcus sp., two types were found: ExaA2, ExaA3, and ExaA5, belonging to quinoproteins which have only PQQ as prosthetic group and which transfer electrons to a separate soluble cytochrome; and ExaA1 and ExaA4, with the characteristics of quinohaemoproteins having a C-terminal cytochrome domain covalently attached to the ADH polypeptide chain. This grouping is supported by the correlation with highest amino acid sequence identity to each other (ExaA2 to ExaA3, 52.5\%; ExaA1 to ExaA4, 46.6\%). Only ExaA5 seems to be an exception; also belonging to quinoproteins, it has a sequence identity of approximately $30 \%$ to all other PQQ-dependent ADH of Azoarcus sp. strain BH72.

A scan of the protein sequences encoded by Azoarcus sp. with the help of the Pfam database (Finn et al. 2006) identified additional putative $\mathrm{ADH}$, all belonging to the group of NAD(P)-dependent ADH. One of these ADH, Azo2700, carries the domain for iron-containing ADH (PF00465). Seven proteins had domains (PF00107 and PF08240) usually found in zinc-binding $\mathrm{ADH}$ or in NADP-dependent quinone oxidoreductases, but only two of these proteins (AdhA and AdhC) possessed the conserved amino acids which are related to the zinc, alcohol, and coenzyme binding (Reid and Fewson 1994; Sun and Plapp 1992). Furthermore, these two showed high amino acid identity to other well-characterized zinc-binding ADH. Therefore, only AdhA and AdhC were considered to be true $\mathrm{ADH}$ while the others were most probably quinone oxidoreductases.

As expected, AdhA and Azo2700 do not carry any predictable signal peptide or transmembrane helices which point to a cytoplasmic localization of the enzymes. Interestingly, for AdhC, two transmembrane helices were predicted between the $\mathrm{N}$-terminal and the C-terminal domain. This indicates an unusual localization in the membrane with an inside-outsideinside orientation.

\section{Not all ADH are important for ethanol utilization.}

In general, Azoarcus sp. strain BH72 utilizes dicarboxylic acids or ethanol as major carbon sources (Reinhold-Hurek et 
al. 1993b). No growth could be observed when other alcohols such as methanol, propanol, or butanol were used. To elucidate the role of the different $\mathrm{ADH}$ in the first reaction step of the ethanol oxidation process, mutants of each gene were constructed through integration of the plasmids pIMGG or p18KGGST into the genome (Table 1). Cultivation of these mutants aerobically on ethanol showed significantly reduced growth rates only when exaA2 and exaA3 were disrupted (Fig. 2A). Interestingly, proteomic studies of strain $\mathrm{BH} 72$ grown under aerobic standard conditions on ethanol revealed only the presence of these two ADH, with ExaA2 being one of the most abundant proteins identified (Hauberg et al. 2010). These results indicate that ExaA2 and ExaA3 are the main ADH in Azoarcus sp.

In a nitrogen-free, microaerobic environment, the growth considerably declined for the mutant BHexaA $2 S$ and $B H e x a A 3 K$ but also for $B H a d h C$ (Fig. 2A), revealing that there are different requirements in ethanol oxidation under different oxygen regimes.

\section{Expression profile of ADH in free-living Azoarcus sp.}

To study whether expression of $a d h$ genes is induced by alcohol, the integration mutants mentioned above were used. Addition of ethanol to cultures cultivated aerobically led to an increased expression of exaA2, exaA3, and $a d h C$ (Fig. 2B). Inductions of $\mathrm{ADH}$ expression varied between factors of three to seven, depending on the gene analyzed, and were even visible at an ethanol concentration as low as $1 \mathrm{mM}$. In a nitrogen-fixing microaerobic environment, expression of exaA2, exaA3, and $a d h C$ were also strongly induced through ethanol addition (Fig. 2B). Moreover, for exaA2 and exaA3, expression was significantly higher under microaerobic versus aerobic conditions (defined by the $t$ test, $P<0.001$ ), which was also reflected by the more pronounced induction factors of seven and ten, respectively.

When cells were cultivated aerobically or microaerobically in a carbon-free medium, an enhanced expression of exaA2, exaA3, and $a d h C$ was also detectable compared with the expression in malate-containing medium, which most probably resulted from starvation (Fig. 2B). Other alcohols such as methanol, propanol, or butanol did not induce expression levels of exaA2, exaA3, and $a d h C$ to the same extent as ethanol. The low induction values which were in a range similar to that of carbon-free medium probably reflect a response to starvation, because strain $\mathrm{BH} 72$ cannot grow on these alcohols.
To investigate the effect of malate on the ethanol-induced expression of $\mathrm{ADH}$, cells were cultivated in the presence of various malate/ethanol mixtures. Results showed that no induction could be observed when malate was present (Fig. 3), even at concentrations of as little as $1 / 10$ of the ethanol concentration. Addition of fumarate, $\alpha$-ketoglutarate, lactate, or pyruvate, all carbon sources metabolized by Azoarcus sp. strain BH72 (Reinhold-Hurek et al. 1993b), to an ethanol-containing medium inhibited induction of $\mathrm{ADH}$ expression as well (data not shown). These observations imply that induction of ADH expression in Azoarcus sp. is subjected to catabolite repression.

\section{$\operatorname{ExaA2}$ and ExaA3 are also expressed during interaction with rice or an ascomycete.}

Azoarcus sp. shows dense colonization of the outer cell layers and the cortex of rice roots cultured gnotobiotically (Hurek et al. 1994). Additionally, in co-culture with the fungal endophyte Acremonium alternatum 2003, also originating from Kallar grass, most cells of strain BH72 adhere tightly to the mycelium and develop intracytoplasmic membrane stacks to which the nitrogenase localizes (Hurek et al. 1995). During both interactions, strain BH72 fixes nitrogen. Interestingly, Karg and Reinhold-Hurek (1996) observed expression of exaA3 during co-cultivation with the ascomycete while ReinholdHurek and associates (2007) noticed expression of the same gene in rice roots. This raised the question of ADH expression during interaction with these two partners. Analyses of protein profiles obtained from inoculated rice roots or from Azoarcusascomycete co-cultivations, both cultured in medium without ethanol addition, identified ExaA 3 as expected but, in addition, ExaA2 (Fig. 4). None of the other ADH were found.

Expression of ExaA2 and ExaA3 in rice roots was also visualized through the presence of GFP fluorescence obtained after inoculation of the roots with the corresponding mutant strains carrying a transcriptional fusion of the ADH-encoding gene to gfp (Fig. 5A and D). Because single-cell fluorescence could only be observed when Azoarcus sp. was cultivated in ethanolcontaining medium (Fig. 5B and E) compared with growth in medium with malate (Fig. $\mathrm{C}$ and F), it can be assumed that ethanol is produced by the eukaryotic partner in sufficiently high concentration to induce expression of these two PQQ-dependent $\mathrm{ADH}$. The adhC mutant strain also showed single-cell GFP fluorescence when cultivated in an ethanol-containing medium, but no fluorescence was detectable in rice roots (data not shown), indicating that this ADH does not play an impor-

Table 1. Bacterial strains

\begin{tabular}{|c|c|c|}
\hline Strain & Relevant characteristics & Source, reference \\
\hline \multicolumn{3}{|l|}{ Escherichia coli } \\
\hline DH10B & 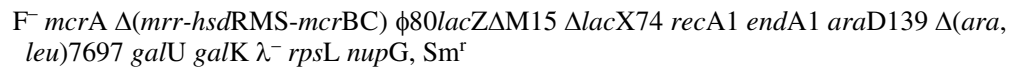 & Invitrogen, Karlsruhe, Germany \\
\hline $\mathrm{DH} 5 \alpha \mathrm{F}^{\prime}$ & $\begin{array}{l}\mathrm{F}^{\prime} / \phi 80 \text { lacZuM15 } \Delta\left(\text { lacZYA-argF) } \mathrm{U} 169 \text { deo } \mathrm{R} \text { recA1 end } \mathrm{A} 1 \text { hsd } \mathrm{R} 17\left(\mathrm{r}_{\mathrm{k}}^{-}, \mathrm{m}_{\mathrm{k}}^{+}\right) \text {phoA }\right. \\
\text { supE44 } \lambda^{-} \text {thi-1 gyrA96 relA1 }\end{array}$ & Invitrogen, Karlsruhe, Germany \\
\hline DH5 $\alpha \mathrm{F}^{\prime}(\mathrm{pRK} 2013)$ & DH5 $\alpha \mathrm{F}^{\prime}$ containing the helper plasmid pRK2013 with $t r a^{+}$, ColE1 replicon, $\mathrm{Km}^{\mathrm{r}}$ & Figurski and Helinski 1979 \\
\hline \multicolumn{3}{|c|}{ 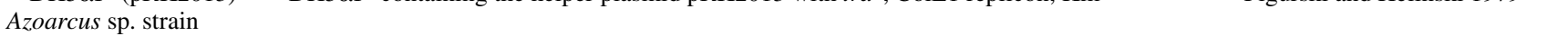 } \\
\hline BH72 & Wild type & Reinhold et al. 1986 \\
\hline BHexaA2S & $\triangle e x a A 2$ with $\Omega$ cassette, $\mathrm{Sm}^{\mathrm{r}}$ & This work \\
\hline BHexaA3K & exaA3:: $\mathrm{Km}$ cassette, $\mathrm{Km}^{\mathrm{r}}$ & This work \\
\hline BHexaA2S-A3K & $\Delta e x a A 2$ with $\Omega$ cassette, exaA $3:: \mathrm{Km}$ cassette, $\mathrm{Km}^{\mathrm{r}} \mathrm{Sm}^{\mathrm{r}}$ & This work \\
\hline BHexaA1 & exaA1::pIMGG at position $937 \mathrm{bp}, \mathrm{Km}^{\mathrm{r}}$ & This work \\
\hline BHexaA2 & exaA2::pIMGG at position $953 \mathrm{bp}, \mathrm{Km}^{\mathrm{r}}$ & This work \\
\hline BHexaA3 & exaA3::pIMGG at position $1365 \mathrm{bp}, \mathrm{Km}^{\mathrm{r}}$ & This work \\
\hline BHexaA4 & exaA4::pK18GGST at position $735 \mathrm{bp}, \mathrm{Km}^{\mathrm{r}}$ & This work \\
\hline BHexaA5 & exaA5::pK18GGST at position $943 \mathrm{bp}, \mathrm{Km}^{\mathrm{r}}$ & This work \\
\hline BHadhA & adhA::pK18GGST at position $582 \mathrm{bp}, \mathrm{Km}^{\mathrm{r}}$ & This work \\
\hline BHadhC & adhC::pK18GGST at position $753 \mathrm{bp}, \mathrm{Km}^{\mathrm{r}}$ & This work \\
\hline BHazo 2700 & azo2700::pK18GGST at position $575 \mathrm{bp}, \mathrm{Km}^{\mathrm{r}}$ & This work \\
\hline
\end{tabular}

\footnotetext{
${ }^{\mathrm{a}} \mathrm{Sm}^{\mathrm{r}}$ and $\mathrm{Km}^{\mathrm{r}}=$ resistant to spectinomycin and kanamycin, respectively.
} 
tant role during the endophytic life of Azoarcus sp. strain BH72.

exaA2 and exaA3 mutants are less competitive than the wild type during colonization of rice roots.

The expression of exaA2 and exaA3 inside of rice roots prompted the question of the importance of these two ADH for endophytic plant colonization by Azoarcus sp. strain BH72. To elucidate this question, marker exchange mutants of exaA2 and exaA3 were constructed (Table 1) and were used in singlestrain set ups of rice infection tests. For both ADH mutants, no significant differences in endophytic colonization compared with the wild-type strain were observed (data not shown). Therefore, a competitive approach was used by inoculating rice roots with a mixture of equal amounts of $\mathrm{BH} 72$ and one mutant strain. This type of plant infection test revealed that both mutants (BHexaA2S and BHexaA3K) were significantly less com-
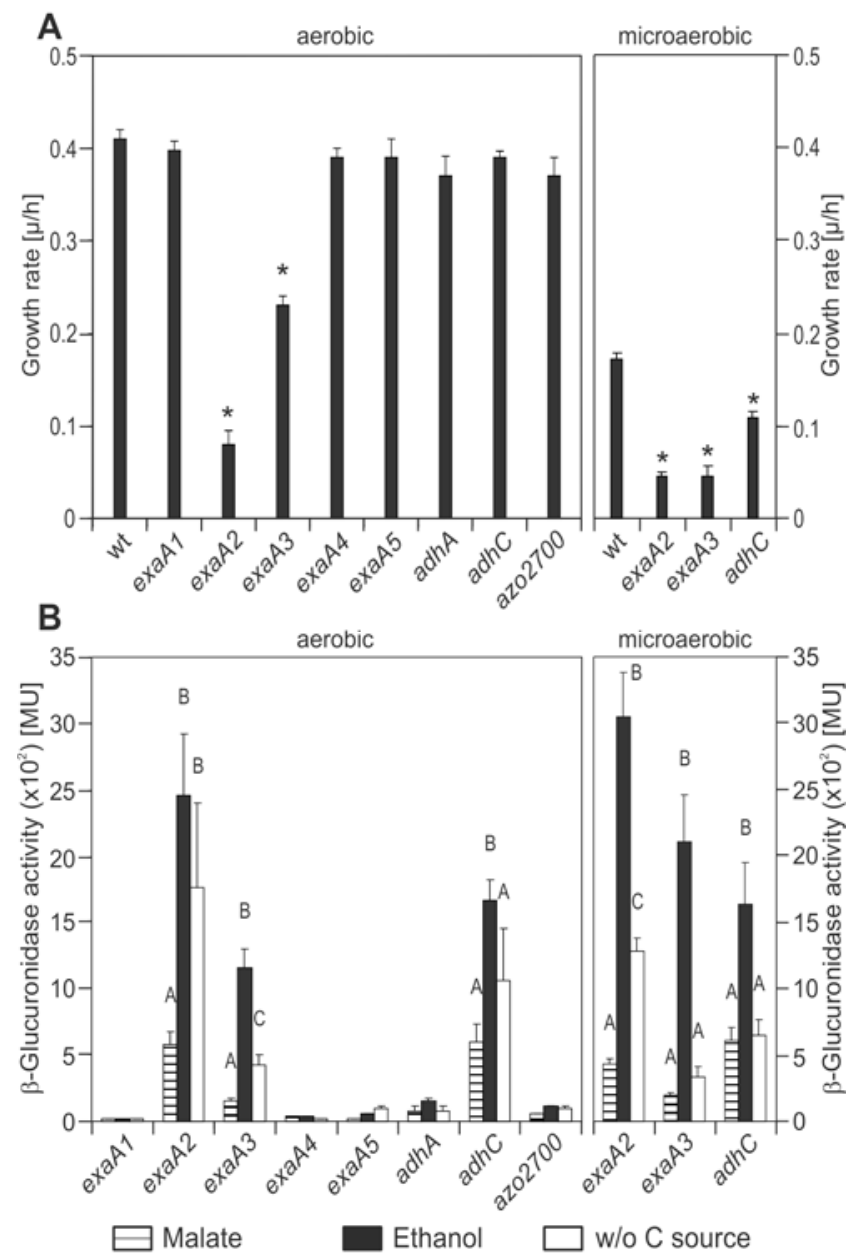

Fig. 2. Functional analyses of the alcohol dehydrogenase (ADH) mutant strains in the free-living stage. Media used were supplemented with 30 $\mathrm{mM}$ malate or ethanol as carbon source, or no carbon source was added (w/o C source). A, Growth rate in culture of $\mathrm{ADH}$ mutants in an adapted SM (synthetic medium) under aerobic conditions or in a nitrogen-free SM medium with a microaerobic environment. Growth rates (average \pm standard deviation [SD]) were calculated from at least four independent cultures when grown aerobically whereas, for microaerobically grown cultures, the growth rates were calculated from at least two independent experiments measured in triplicate. Asterisks show significant differences between mutants versus wild type $(P<0.001)$. B, Promoter activity of the ADHencoding genes in nitrogen-free SM under aerobic or microaerobic conditions. $\beta$-Glucuronidase activity is given in Miller units (average \pm SD) determined from at least four independent cultures measured in duplicate. Different letters above bars indicate significance among the average $(P<0.001)$. petitive than the wild type (Table 2 ). The results indicate the importance of exaA 2 and exaA3 for plant colonization, conveying a competitive advantage over other colonizing bacteria lacking these genes. To address the question of whether the lack of both $a d h$ genes might affect colonization more strongly, a double mutant, BHexaA2S-A3K, was constructed (Table 1) and tested for endophytic establishment in rice roots in comparison with the wild type (Table 2 ). With only $14.5 \%$ of the colonizing bacteria being $B H \operatorname{exa} A 2 S-A 3 K$, endophytic establishment was even less efficient than observed for single $\mathrm{ADH}$ mutants. This supported the assumption that ethanol is present in rice roots and an important carbon source for Azoarcus sp. strain BH72 during apoplastic colonization.

\section{DISCUSSION}

Although some of the details of the endophytic lifestyle of Azoarcus sp. strain $\mathrm{BH} 72$ are characterized (Krause et al. 2006), little is known about the physicochemical properties of root systems which allow BH72 to survive, multiply, and fix nitrogen. Particularly, the carbon sources which are utilized for endophytic activity are yet unidentified. In order to probe for nutrients provided by the plant in the vicinity of the bacteria, we applied an approach which makes use of inducible bacterial promoters. Therefore, an insertion library of Azoarcus sp. strain BH72 was constructed, whereby promoters were randomly fused to the marker gene $g f p$, similarly to what was described by Cowie and associates (2006). A microtiter-plate based screening for GFP activity was performed to identify Azoarcus genes whose expressions were induced in the presence of carbon sources, especially those thought to be available in the plant apoplast. When the culture medium was supplemented with ethanol, one recombinant Azoarcus strain showed high GFP fluorescence. Sequence analysis of the $g f p$ flanking region revealed that the trapped gene encodes a PQQdependent ADH, named ExaA3. Scanning of the complete Azoarcus genome discovered four additional genes encoding PQQ-dependent ADH, as well as three coding for NAD(P)dependent ADH (Krause et al. 2006). Having eight potential ADH, the genus Azoarcus seems to be well equipped for different environmental conditions offering various alcohols.

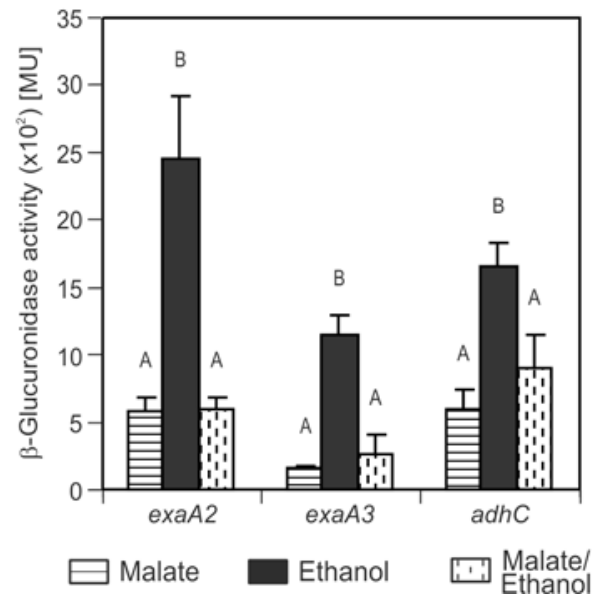

Fig. 3. Malate repression of ethanol-induced alcohol dehydrogenase (ADH) expression. An Azoarcus sp. was cultivated under aerobic conditions in nitrogen-free SM (synthetic medium) supplemented with $30 \mathrm{mM}$ malate, $30 \mathrm{mM}$ ethanol, or a mixture of $3 \mathrm{mM}$ malate and $30 \mathrm{mM}$ ethanol. $\beta$-Glucuronidase activity is specified as Miller units (average \pm standard deviation) determined from at least four independent cultures measured in duplicate. Significantly different activities are indicated by different letters above the bars $(P<0.001)$. 
Quite a number of bacteria can obtain their energy for growth by oxidizing ethanol. Therefore, the use of ethanol as carbon source is not exceptional to Azoarcus strains. Also, among the nitrogen-fixing bacteria, this is not a surprising feature; for example, some rhizobia and bradyrhizobia are capable of growing on this carbon source (Sadowsky and Bohlool 1986). Additionally, the presence of multiple ADH is not unique to Azoarcus sp. strain BH72 (for example, Pseudomonas butanovora) which, in alcohol-utilizing bacteria, probably reflects the habitat to which the organism is adapted (Radianingtyas and Wright 2003; Vangnai and Arp 2001). The habitat of Azoarcus sp. is mainly the apoplastic space of the aerenchyma of grass roots grown under waterlogged conditions (Reinhold-Hurek and Hurek 1998). Rice, one of the grasses which can be colonized by Azoarcus sp. strain $\mathrm{BH} 72$, grown under these conditions, is subjected to hypoxia and even to anoxia, which induces morphological modification and metabolic changes. Adaptation of the metabolism includes a switch of the respiration from the oxidative to the fermentation pathway, leading to production and accumulation of ethanol (Agarwal and Grover 2006; Mustroph and Albrecht 2003). However, in aerated rice roots, ethanol accumulation can also be observed (Mustroph et al. 2006). Because ethanol can pass directly through cell membranes by simple diffusion, this compound would appear in the plant apoplast and, therefore, would be available for Azoarcus strains.

Under pure culture conditions, expression of three of the eight ADH from Azoarcus sp. strain BH72 was induced by ethanol, of which two, the PQQ-dependent ADH ExaA2 and ExaA3, showed even higher induction under nitrogen-fixing conditions. Induction of gene expression by ethanol indicates that these $\mathrm{ADH}$ are involved in the oxidation of ethanol, feeding it into the central metabolism pathway as carbon and an energy source for bacterial growth. Substrate specificity of the other five ADH remains unclear because, in culture, no induction of gene expression could be observed by either ethanol or methanol, propanol, or butanol. Further studies will attempt to clarify the substrate specificity and the physiological function of these additional ADH in Azoarcus sp. strain BH72.

Strong expression of the two PQQ-dependent ADH (ExaA2 and ExaA3) was also visible inside rice roots. Additionally, the presence of these ADH conferred an advantage in endophytic
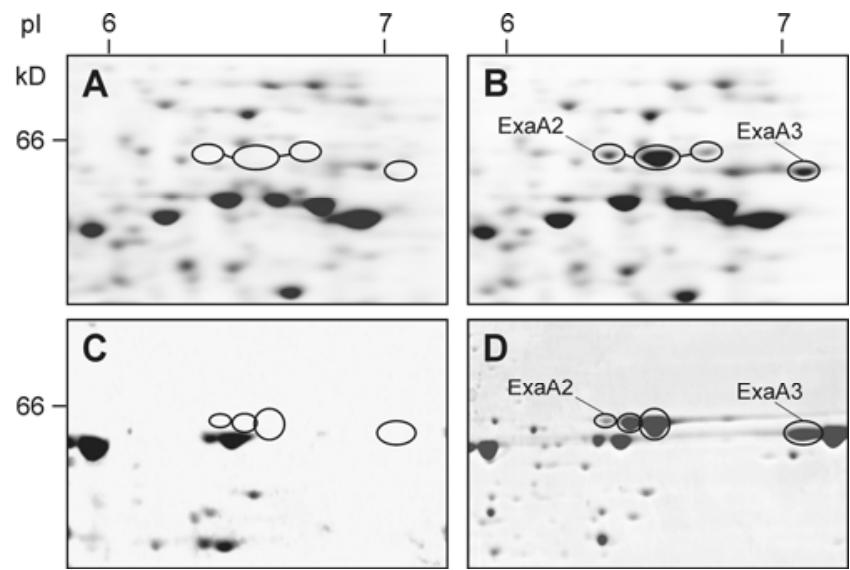

Fig. 4. Identification of ExaA2 and ExaA3 during interaction of Azoarcus sp. strain $\mathrm{BH} 72$ with rice or an ascomycete. Extracts of total proteins from A, uninoculated control rice roots; $\mathbf{B}$, rice roots inoculated with $\mathrm{BH} 72 ; \mathbf{C}$, Strain BH72 grown under microaerobic nitrogen-fixing conditions; or D, Strain BH72 co-cultivated with the ascomycete Acremonium alternatum strain 2003 were separated by two-dimensional gel electrophoresis. Shown are close-ups of stained gels. Circled protein spots are missing in the corresponding control. Identification was performed by matrix-assisted laser desorption ionization time-of-flight or liquid chromatography tandem mass spectrometry. plant colonization under competitive conditions. Therefore, ethanol seems to occur in sufficiently high concentration within the plant to direct bacterial ADH expression. Interestingly, in pure culture, induction of ADH by ethanol was subjected to catabolite repression by the presence of fumarate, $\alpha$ ketoglutarate, lactate, malate, or pyruvate. The involvement of catabolite repression in $a d h$ gene expression was already demonstrated for Corynebacterium glutamicum (Kotrbova-Kozak et al. 2007) and, therefore, is not an unique feature for Azoarcus sp. strain BH72. However, while these carbon sources can be metabolized by strain BH72 (Reinhold-Hurek et al. 1993b) and while expression of ExaA2 and ExaA3 occurs within the plant, fumarate, $\alpha$-ketoglutarate, lactate, malate, or pyruvate are either absent or at least present only in very low concentrations in the apoplastic fluid under the conditions studied. Thus, it is likely that ethanol serves as abundant carbon source for the endophytic life of strain BH72.

Moreover, additional regulatory circuits of relevance in the plant-microbe interaction might be affected by the presence of ethanol. The activity of hydrolytic enzymes that are likely to degrade plant cell wall components such as surface-bound exoglycanase and endoglucanase is enhanced in strain BH72 in the presence of ethanol (Reinhold-Hurek et al. 1993a). Indeed, the expression of the gene encoding the endoglucanase EglA was induced by ethanol. Because this endoglucanase was found to be involved in intracellular colonization of and systemic spreading in rice (Reinhold-Hurek et al. 2006), the endophytic interaction is likely to be affected by ethanol beyond catabolism.

In rice roots, $98 \%$ of the fermentatively produced ethanol is immediately released from the tissue into the environment (Bertani et al. 1980; Mustroph et al. 2006). This may serve for Azoarcus strains as an attractant to enter the roots. Once inside the root, the endophytes consume the ethanol and, thus, might help the plant to keep concentrations of ethanol below the critical level of toxicity. The plant benefit of this consumption might be an increased tolerance to hypoxic conditions. Experimental analyses need to be performed to elucidate this potentially additional role of Azoarcus sp. strain BH72 in the endophytic interaction with rice.

\section{MATERIALS AND METHODS}

\section{Bacterial strains and growth conditions.}

Bacterial strains used are listed in Table 1. Escherichia coli was grown in Luria-Bertani medium (Sambrook et al. 1989) at $37^{\circ} \mathrm{C}$ with appropriate antibiotics added. Azoarcus sp. strain BH72 and its mutant strains were cultivated aerobically at $37^{\circ} \mathrm{C}$ in a modified VM (Voll medium), in which the beef extract was replaced by $0.3 \%$ peptone containing malate (Reinhold-Hurek et al. 1993b) or ethanol (Hurek et al. 1995; Reinhold-Hurek et al. 1993a) as carbon source. Additionally, growth of BH72 was performed in an adapted SM (synthetic medium) (Reinhold et al. 1985) devoid of yeast extract and containing ethanol (6 ml/liter) instead of malate. Antibiotics used were kanamycin and spectinomycin at a final concentration of 30 and $40 \mu \mathrm{g} / \mathrm{ml}$, respectively. To determine the GUS or GFP activity, bacterial cells were culti-

Table 2. Bacterial competition during plant colonization

\begin{tabular}{|c|c|c|}
\hline $\begin{array}{l}\text { Strain in competition } \\
\text { with } \mathrm{BH} 72\end{array}$ & $\begin{array}{l}\text { Percentages of colonizing } \\
\text { bacteria (average } \pm \text { SD) }\end{array}$ & $P$ value \\
\hline $\mathrm{BH} \operatorname{exaA2S}$ & $30.3 \pm 4.6$ & $4.9 \times 10^{-4}$ \\
\hline ВНехаA $3 K$ & $32.7 \pm 11.7$ & $1.1 \times 10^{-2}$ \\
\hline ВНеxaA2S-A3K & $14.5 \pm 4.4$ & $3.9 \times 10^{-5}$ \\
\hline
\end{tabular}

${ }^{a}$ Analyses based on a minimum of 27 plants per mixture combined from three independent trials. SD $=$ standard deviation. 
vated aerobically in nitrogen-free SM with different carbon sources at a final concentration of $30 \mathrm{mM}$. Microaerobic growth was performed under nitrogen-fixing conditions in nitrogen-free SM with ethanol in either a rubber-stopper-sealed Erlenmeyer flask with an initial concentration of $1.2 \% \mathrm{O}_{2}$ in the $\mathrm{N}_{2}$ headspace or a 2-liter fermenter (Biostat B; Braun Biotech, Melsungen, Germany) with a regulated oxygen supply of $0.12 \%$ in $\mathrm{N}_{2}$. Co-cultivation of strain BH72with the ascomycete Acremonium alternatum 2003 was carried out as described by Hurek and associates (1995) at $30^{\circ} \mathrm{C}$ until oxygen in the gas phase had diminished to $4 \%$.

\section{DNA protocols and sequence data analysis.}

Recombinant DNA techniques were performed following established protocols (Sambrook et al. 1989). DNA sequencing was carried out by the dideoxynucleotide chain method on an ALFexpress automated sequencer (GE Healthcare, Freiburg, Germany).

Sequence comparisons were conducted through the BLAST program (Altschul et al. 1997) of the National Center for Biotechnology Information (NCBI; Bethesda, MD, U.S.A.). Domain structures of proteins were analyzed by the conserved domain database at NCBI (Marchler-Bauer et al. 2007) or by the Pfam database of the Wellcome Trust Sanger Institute (Hinxton, U.K.) (Finn et al. 2006). Signal peptides were predicted with SignalP 3.0 (Bendtsen et al. 2004) while transmembrane helices were identified by using TMHMM 2.0 (Krogh et al. 2001), both from the Center for Biological Sequences Analysis (Lyngby, Denmark).

\section{Construction of a transcriptional fusion library} to $g f p$ and $g u s A$ in Azoarcus sp. strain BH72.

A plasmid library was constructed in pIMGG (Fig. 1) by digestion of the vector with SalI and partial fill ups of the overhanging ends with dCTP and dTTP. Chromosomal DNA of Azoarcus sp. strain BH72 was partly digested with Sau3AI and size fractionated through gel electrophoresis to 2 to $5 \mathrm{~kb}$. Overhangs were filled in by using dATP and dGTP. After ligation, recombinant plasmids were electroporated into $E$. coli DH10B generating $1.5 \times 10^{3}$ colonies. Each plasmid was separately mobilized into strain $\mathrm{BH} 72$ via triparental conjugation. In all, $1.25 \times 10^{3}$ recombinants were obtained by selecting for the vector-encoded $\mathrm{Km}^{\mathrm{r}}$ marker, indicating a single-crossover event into the Azoarcus genome.

\section{Microtiter-plate based screening \\ for GFP expression of the library.}

Recombinant Azoarcus clones were into transferred into DeepWell plates (with 96 wells each) containing $1 \mathrm{ml}$ of VM and were grown overnight at $37^{\circ} \mathrm{C}$. After two times of washing the bacteria with nitrogen-free SM without carbon source, cells were subjected in parallel to flat-bottom microtiter plates with $100 \mu \mathrm{l}$ of nitrogen-free SM containing 52 different carbon sources at a final concentration of $30 \mathrm{mM}$ followed by an incubation of $4 \mathrm{~h}$ at $37^{\circ} \mathrm{C}$. Expression of GFP was directly monitored by scanning the microtiter-plates with the fluorescence imager Typhoon 8600 (GE Healthcare, Freiburg, Germany) (excitation wavelength $532 \mathrm{~nm}$, emission filter $526 \mathrm{SP}$ ). Relative fluorescence was normalized against an optical density at
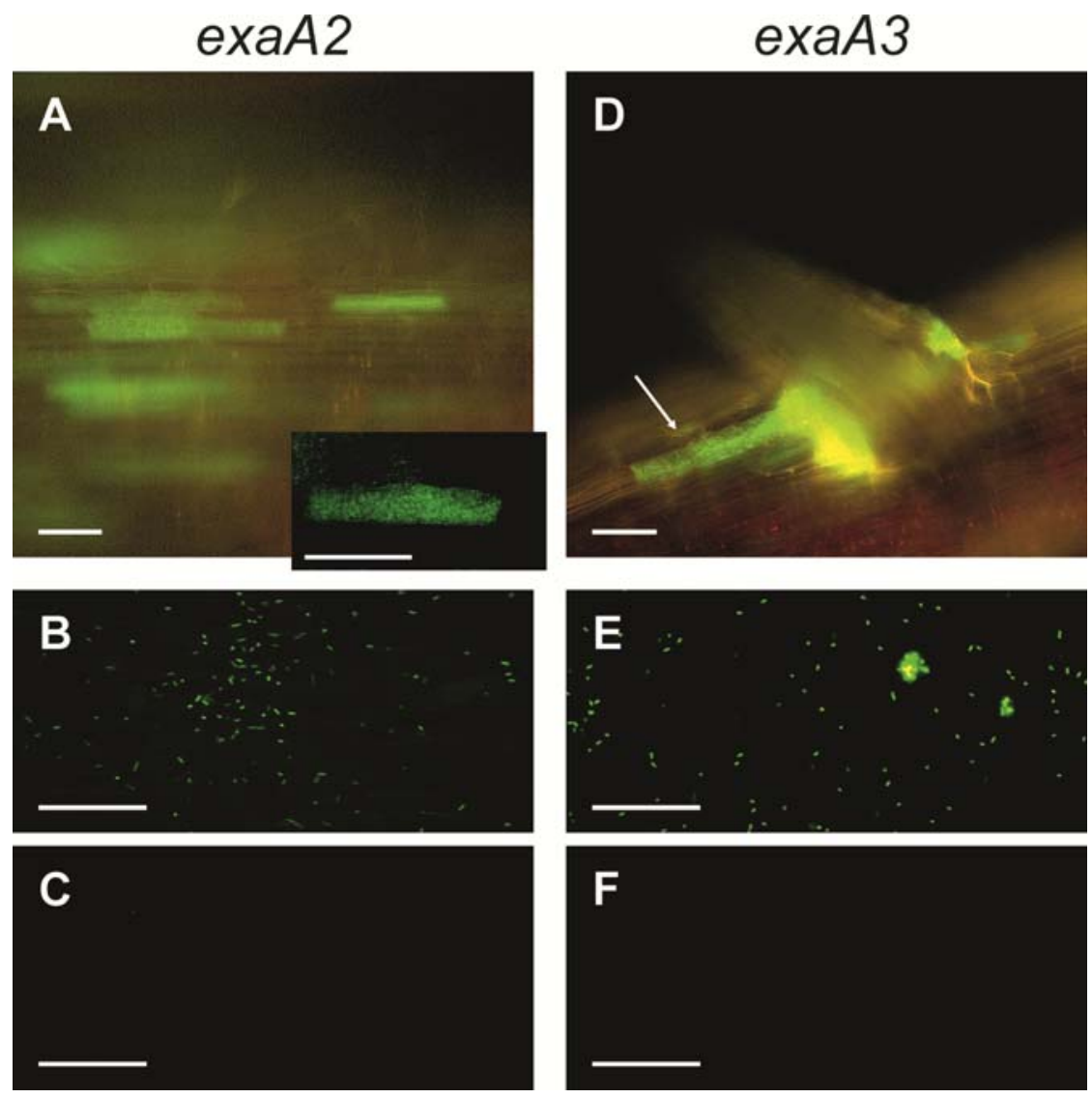

Fig. 5. Expression profile of the bacterial genes exaA2 or exaA3 in rice roots. The figure shows representative photographs. Fluorescence detection inside of $\mathbf{A}$ and $\mathbf{D}$, inoculated rice roots or $\mathbf{B}$ and $\mathbf{E}$, cultures supplemented with ethanol. $\mathbf{C}$ and $\mathbf{F}$, No fluorescence was visible when malate was used as carbon source. Roots of rice seedlings were inoculated with BHexaA2S and grown for 14 days gnotobiotically whereas, for BHexaA3K, seedlings were placed into bacterial suspension and incubated for 3 days in the growth chamber (short-term invasion analysis). Bacterial cultures were grown overnight. D is taken from Reinhold-Hurek and associates (2007). Settings of the fluorescence microscope and the video camera were equal for micrographs of roots and bacterial cultures. Scale bars $=50 \mu \mathrm{m}$. 
$570 \mathrm{~nm}\left(\mathrm{OD}_{570}\right)$ obtained with the Multiskan Ascent (Thermo Scientific, Waltham, MA, U.S.A.).

\section{Disruption of genes encoding ADH.}

exaA2 and exaA3 were disrupted by marker exchange mutagenesis. DNA segments to be deleted were replaced by an antibiotic resistance cassette $\left(\mathrm{Sm}^{\mathrm{r}} / \mathrm{Sp}^{\mathrm{r}}\right.$ for exaA2 obtained from the plasmid $\mathrm{pH} 45 \Omega$ [Prentki and Krisch 1984] and $\mathrm{Km}^{\mathrm{r}}$ for exaA3 taken from pUC4K [GE Healthcare]). The recombinant plasmids were either electroporated into the Azoarcus sp. (exaA3 on pUC19) (Yanisch-Perron et al. 1985) or used for subcloning of the modified DNA fragment into the mobilizable vector pK18mob2 (Kirchner and Tauch 2003), which was then transferred into Azoarcus sp. by triparental conjugation (exaA2). Double-crossover events at homologous sites resulted in antibiotic-resistant strains (Table 1). The plasmid integration mutagenesis was performed to generate transcriptional fusions of the genes of interest to $g f p$ and $g u s A$ by amplifying appropriate parts of the genes followed by cloning of the polymerase chain reaction products into the vector pIMGG or $\mathrm{pK} 18 \mathrm{GGST}$ (Fig. 1). The resulting plasmids were transferred into Azoarcus sp. by triparental conjugation. The vector-encoded $\mathrm{Km}^{\mathrm{r}}$ marker allowed selection of strains with the plasmid integrated into the chromosome (Table 1). Correct integration events were confirmed by Southern blot analysis.

\section{Analyses of growth rates of mutant strains.}

To evaluate growth of the mutants compared with the wild type, strains were precultured in VM with ethanol or malate overnight at 30 or $37^{\circ} \mathrm{C}$. Cells were centrifuged, washed twice, and resuspended in adapted SM for aerobic growth or in nitrogen-free SM for microaerobic growth in the fermenter. Media were supplement with carbon sources to a final concentration of $30 \mathrm{mM}$. Cultures were adjusted to an $\mathrm{OD}_{600}$ of $0.05 / 0.01$ (aerobic/microaerobic) and further incubated at $37^{\circ} \mathrm{C}$. Culture samples were taken at different time points during exponential growth, and OD was determined at $600 \mathrm{~nm}$. Growth rates were calculated for each culture and averaged. Data were statistically analyzed by a two-tailed $t$ test.

\section{GUS activity in free-living Azoarcus mutant strains.}

Cultures were grown in VM with malate at $30^{\circ} \mathrm{C}$ overnight. Cells were collected by centrifugation, washed twice with nitrogen-free SM without carbon source, and finally adjusted to an $\mathrm{OD}_{600}$ of 0.3 in nitrogen-free SM supplemented with $30 \mathrm{mM}$ different carbon sources. After additional incubation of $6 \mathrm{~h}$ under aerobic or nitrogen-fixing microaerobic conditions at $37^{\circ} \mathrm{C}$, two 1-ml samples were taken. Bacterial cells were pelleted and resuspended in $2 \mathrm{ml}$ of GUS buffer ( $50 \mathrm{mM}$ sodium phosphate, $\mathrm{pH} \mathrm{7}$, and $10 \mathrm{mM} \beta$-mercaptoethanol). To permeabilize the bacterial cells, $0.5 \mathrm{ml}$ of the suspension was treated for $10 \mathrm{~min}$ at $37^{\circ} \mathrm{C}$ with $50 \mu \mathrm{l}$ of lysis buffer $(0.5 \times \mathrm{TE}, \mathrm{pH} 8$, and $0.05 \%$ sodium dodecyl sulfate) while the $\mathrm{OD}_{600}$ of the cells was determined from the remaining suspension. Quantitative GUS activity assays were performed with $p$-nitrophenyl- $\beta$-D-glucuronide as described by Jefferson and associates (1986). Activity of the GUS was calculated as Miller units from each culture. The average was calculated and significance was determined by using the Tukey-Kramer multiple comparison test.

\section{Plant growth condition and inoculation tests.}

Rice plants used were Oryza sativa subsp. indica 'IR36' obtained from the International Rice Research Institute (Los Banos, Philippines). Rice grains were surface sterilized and germinated on agar plates according to Hurek and associates (1994) with the modifications that the washing steps with distilled water after sterilization were elongated to $1 \mathrm{~h}$ and per- formed three times while the germination plates contained only $10 \%$ agar. Germination took place for 3 to 4 days in the dark at $37^{\circ} \mathrm{C}$ succeeded by an additional day in the growth chamber with a day time of $14 \mathrm{~h}$ at $30^{\circ} \mathrm{C}$ and $80 \%$ relative humidity, a light intensity of $23 \mathrm{kLux}$, and a night time of $10 \mathrm{~h}$ at $30^{\circ} \mathrm{C}$. Germinated seedlings were inoculated with individual bacterial strains for the single strain set-up or for the competitive approach with a 1:1 mixture of the wild-type and a mutant strain, as described by Egener and associates (1999), with the exception that the nitrogen-free plant medium contained malate at $20 \mathrm{mg} / \mathrm{liter}$. Cultivation of plants was performed gnotobiotically for 14 days in the growth chamber or in the greenhouse where conditions were similar to the growth chamber other than a 12-h light time in addition to the natural daynight rhythm. For short-term invasion analyses, seedlings were placed into $1 \mathrm{ml}$ of bacterial suspension with $5 \times 10^{8}$ cells $/ \mathrm{ml}$ and incubated for 3 days in the growth chamber (ReinholdHurek et al. 2006). Expression of GFP was monitored by fluorescence microscopy with a Zeiss Axioplan 2 (Carl Zeiss AG, Jena, Germany) according to Egener and associates (1998). To quantify endophytic colonization of rice roots, plants were harvested after 14 days. Roots were treated by ultrasonification and homogenized (Böhm et al. 2007). Dilutions of the homogenate were plated out on SM to determine CFU counts as degree of colonization. In the competitive approach, 50 colonies were randomly transferred in parallel to VM-ethanol plates with and without appropriate antibiotics in order to distinguish the mutant strain from the wild type. All competition experiments were repeated in three independent trials. The percentage of colonizing mutant strain was calculated, averaged, and statistically analyzed by a two-tailed $t$ test.

\section{Protein analyses and identification.}

Preparation of total protein extracts from control and treated roots as well as separation of the proteins by two-dimensional gel electrophoresis and protein identification through matrixassisted laser desorption ionization time-of-flight (MALDITOF) or liquid chromatography tandem mass spectrometry were performed as described by Miché and associates (2006).

For extraction of bacterial proteins, Azoarcus sp. strain $\mathrm{BH} 72$ grown in co-culture with the ascomycete was first separated from the fungal mycelium and then pelleted (Hurek et al. 1995). Cells were resuspended in $50 \mathrm{mM}$ sodium phosphate buffer $(\mathrm{pH} 7)$ and disrupted by four passages through a French press $\left(1,500 \mathrm{lb} / \mathrm{in}^{2}{ }^{2}\right)$. After centrifugation $(20 \mathrm{~min}$ at $20,000 \times g$, $\left.4^{\circ} \mathrm{C}\right)$, the extracts were fractionated by ultracentrifugation $(2 \mathrm{~h}$ at $\left.200,000 \times g, 4^{\circ} \mathrm{C}\right)$. Proteins from the supernatant were precipitated by trichloroacetic acid. Pellets were dissolved in extraction buffer and further processed as described by Hauberg and associates (2010). Then, proteins were subjected to twodimensional gel electrophoresis (Hauberg et al. 2010; Hurek et al. 1995) and further identified by MALDI-TOF with the Proteome-Analyzer 4700 (Applied Biosystems, Foster City, CA, U.S.A.) (Hauberg et al. 2010).

\section{ACKNOWLEDGMENTS}

This work was supported partially by grants to B. Reinhold-Hurek from the German Research Foundation (DFG) as subproject Re756/6-1 of the Priority Program SPP 717, and from the Federal Ministry of Education and Science (BMBF) in the framework GenoMik, 031U213D. We thank T. Fründ and F. Meyerjürgens for technical assistance and U. Völker and C. Scharf for the protein identification.

\section{LITERATURE CITED}

Agarwal, S., and Grover, A. 2006. Molecular biology, biotechnology and genomics of flooding-associated low $\mathrm{O}_{2}$ stress response in plants. Crit. 
Rev. Plant Sci. 25:1-21.

Altschul, S. F., Madden, T. L., Schaffer, A. A., Zhang, J., Zhang, Z., Miller, W., and Lipman, D. J. 1997. Gapped BLAST and PSI-BLAST: A new generation of protein database search programs. Nucleic Acids Res. 25:3389-3402.

Bendtsen, J. D., Nielsen, H., von Heijne, G., and Brunak, S. 2004. Improved prediction of signal peptides: SignalP 3.0. J. Mol. Biol. 340:783-795.

Bertani, A., Brambilla, I., and Menegus, F. 1980. Effect of anaerobiosis on rice seedlings: Growth, metabolic rate, and fate of fermentation products. J. Exp. Bot. 31:325-331

Böhm, M., Hurek, T., and Reinhold-Hurek, B. 2007. Twitching motility is essential for endophytic rice colonization by the $\mathrm{N}_{2}$-fixing endophyte Azoarcus sp. strain BH72. Mol. Plant-Microbe Interact. 20:526-533.

Cowie, A., Cheng, J., Sibley, C. D., Fong, Y., Zaheer, R., Patten, C. L., Morton, R. M., Golding, G. B., and Finan, T. M. 2006. An integrated approach to functional genomics: Construction of a novel reporter gene fusion library for Sinorhizobium meliloti. Appl. Environ. Microbiol. 72:7156-7167.

Dörr, J., Hurek, T., and Reinhold-Hurek, B. 1998. Type IV pili are involved in plant-microbe and fungus-microbe interactions. Mol. Microbiol. 30:7-17.

Egener, T., Hurek, T., and Reinhold-Hurek, B. 1998. Use of green fluorescent protein to detect expression of nif genes of Azoarcus sp. BH72, a grass-associated diazotroph, on rice roots. Mol. Plant-Microbe Interact. 11:71-75.

Egener, T., Hurek, T., and Reinhold-Hurek, B. 1999. Endophytic expression of nif genes of Azoarcus sp. strain BH72 in rice roots. Mol. PlantMicrobe Interact. 12:813-819.

Figurski, D. H., and Helinski, D. R. 1979. Replication of an origin-containing derivative of plasmid RK2 dependent on a plasmid function provided in trans. Proc. Natl. Acad. Sci. U.S.A. 76:1648-1652.

Finn, R. D., Mistry, J., Schuster-Bockler, B., Griffiths-Jones, S., Hollich, V., Lassmann, T., Moxon, S., Marshall, M., Khanna, A., Durbin, R., Eddy, S. R., Sonnhammer, E. L., and Bateman, A. 2006. Pfam: Clans, web tools and services. Nucleic Acids Res. 34:D247-251.

Hauberg, L., Schmidt, F., Scharf, C., Dörr, J., Völker, U., and ReinholdHurek, B. 2010. Proteomic characterization of a pilR regulatory mutant of Azoarcus sp. strain BH72 with the aid of gel-based and gel-free approaches. Proteomics 10:458-469.

Hurek, T., Reinhold-Hurek, B., Van Montagu, M., and Kellenberger, E. 1994. Root colonization and systemic spreading of Azoarcus sp. strain BH72 in grasses. J. Bacteriol. 176:1913-1923.

Hurek, T., Van Montagu, M., Kellenberger, E., and Reinhold-Hurek, B. 1995. Induction of complex intracytoplasmic membranes related to nitrogen fixation in Azoarcus sp. BH72. Mol. Microbiol. 18:225-236.

Jefferson, R. A., Burgess, S. M., and Hirsh, D. 1986. Beta glucuronidase from Escherichia coli as a gene-fusion marker. Proc. Natl. Acad. Sci. U.S.A. 83:8447-8451

Karg, T., and Reinhold-Hurek, B. 1996. Global changes in protein composition of $\mathrm{N}_{2}$-fixing Azoarcus sp. strain $\mathrm{BH} 72$ upon diazosome formation. J. Bacteriol. 178:5748-5754.

Kirchner, O., and Tauch, A. 2003. Tools for genetic engineering in the amino acid-producing bacterium Corynebacterium glutamicum. J. Biotechnol. 104:287-299.

Kotrbova-Kozak, A., Kotrba, P., Inui, M., Sajdok, J., and Yukawa, H. 2007. Transcriptionally regulated $a d h \mathrm{~A}$ gene encodes alcohol dehydrogenase required for ethanol and $n$-propanol utilization in Corynebacterium glutamicum R. Appl. Microbiol. Biotechnol. 76:1347-1356.

Krause, A., Ramakumar, A., Bartels, D., Battistoni, F., Bekel, T., Boch, J., Böhm, M., Friedrich, F., Hurek, T., Krause, L., Linke, B., McHardy, A., Sarkar, A., Schneiker, S., Syed, A. A., Thauer, R., Vorhölter, F., Weidner, S., Pühler, A., Reinhold-Hurek, B., Kaiser, A., and Goesmann, A. 2006. Genomic insights into the lifestyle of the mutualistic, $\mathrm{N}_{2}$-fixing grass endophyte Azoarcus sp. strain BH72. Nat. Biotechnol. 24:1385-1391.

Krogh, A., Larsson, B., von Heijne, G., and Sonnhammer, E. L. 2001. Predicting transmembrane protein topology with a hidden Markov model: Application to complete genomes. J. Mol. Biol. 305:567-580.

Marchler-Bauer, A., Anderson, J. B., Derbyshire, M. K., DeWeese-Scott,
C., Gonzales, N. R., Gwadz, M., Hao, L., He, S., Hurwitz, D. I., Jackson, J. D., Ke, Z., Krylov, D., Lanczycki, C. J., Liebert, C. A., Liu, C., Lu, F., Lu, S., Marchler, G. H., Mullokandov, M., Song, J. S., Thanki, N., Yamashita, R. A., Yin, J. J., Zhang, D., and Bryant, S. H. 2007. CDD: A conserved domain database for interactive domain family analysis. $\mathrm{Nu}$ cleic Acids Res. 35:D237-240.

Miché, L., Battistoni, F., Gemmer, S., Belghazi, M., and Reinhold-Hurek, B. 2006. Upregulation of jasmonate-inducible defense proteins and differential colonization of roots of Oryza sativa cultivars with the endophyte Azoarcus sp. Mol. Plant-Microbe Interact. 19:502-511.

Mustroph, A., and Albrecht, G. 2003. Tolerance of crop plants to oxygen deficiency stress: Fermentative activity and photosynthetic capacity of entire seedlings under hypoxia and anoxia. Physiol. Plant. 117:508-520.

Mustroph, A., Boamfa, E. I., Laarhoven, L. J., Harren, F. J., Albrecht, G., and Grimm, B. 2006. Organ-specific analysis of the anaerobic primary metabolism in rice and wheat seedlings. I: Dark ethanol production is dominated by the shoots. Planta 225:103-114.

Prentki, P., and Krisch, H. M. 1984. In vitro insertional mutagenesis with a selectable DNA Fragment. Gene 29:303-314.

Radianingtyas, H., and Wright, P. C. 2003. Alcohol dehydrogenases from thermophilic and hyperthermophilic archaea and bacteria. FEMS (Fed Eur. Microbiol. Soc.) Microbiol. Rev. 27:593-616.

Reid, M. F., and Fewson, C. A. 1994. Molecular characterization of microbial alcohol dehydrogenases. Crit. Rev. Microbiol. 20:13-56.

Reinhold, B., Hurek, T., and Fendrik, I. 1985. Strain-specific chemotaxis of Azospirillum spp. J. Bacteriol. 162:190-195.

Reinhold, B., Hurek, T., Niemann, E.-G., and Fendrik, I. 1986. Close association of Azospirillum and diazotrophic rods with different root zones of Kallar grass. Appl. Environ. Microbiol. 52:520-526.

Reinhold-Hurek, B., and Hurek, T. 1998. Life in grasses: Diazotrophic endophytes. Trends Microbiol. 6:139-144.

Reinhold-Hurek, B., Hurek, T., Claeyssens, M., and Van Montagu, M. 1993a. Cloning, expression in Escherichia coli, and characterization of cellulolytic enzymes of Azoarcus sp., a root-invading diazotroph. J. Bacteriol. 175:7056-7065.

Reinhold-Hurek, B., Hurek, T., Gillis, M., Hoste, B., Vancanneyt, M., Kersters, K., and De Ley, J. 1993b. Azoarcus gen. nov., nitrogen-fixing proteobacteria associated with roots of Kallar grass (Leptochloa fusca (L.) Kunth) and description of two species Azoarcus indigens sp. nov. and Azoarcus communis sp. nov. Int. J. Syst. Bacteriol. 43:574-584.

Reinhold-Hurek, B., Tan, Z., and Hurek, T. 2005. Genus Azoarcus. Pages 890-901 in: Bergey's Manual of Systematic Bacteriology, Vol. 2. G. M. Garrity, ed. Springer Verlag, New York.

Reinhold-Hurek, B., Maes, T., Gemmer, S., Van Montagu, M., and Hurek, T. 2006. An endoglucanase is involved in infection of rice roots by the not cellulose-metabolizing endophyte Azoarcus sp. BH72. Mol. PlantMicrobe Interact. 19:181-188.

Reinhold-Hurek, B., Krause, A., Leyser, B., Miché, L., and Hurek, T. 2007. The rice apoplast as a habitat for endophytic $\mathrm{N}_{2}$-fixing bacteria Pages 427-443 in: The Apoplast of Higher Plants: Compartment of Storage, Transport, and Reactions. B. Sattelmacher and W. J. Horst, eds. Springer, Dordrecht, The Netherlands.

Sadowsky, M. J., and Bohlool, B. B. 1986. Growth of fast- and slow-growing rhizobia on ethanol. Appl. Environ. Microbiol. 52:951-953.

Sambrook, J., Fritsch, E. F., and Maniatis, T. 1989. Molecular Cloning: A Laboratory Manual. Cold Spring Harbor Laboratory Press, Cold Spring Harbor, NY, U.S.A

Sun, H. W., and Plapp, B. V. 1992. Progressive sequence alignment and molecular evolution of the Zn-containing alcohol dehydrogenase family. J. Mol. Evol. 34:522-535.

Toyama, H., Mathews, F. S., Adachi, O., and Matsushita, K. 2004. Quinohemoprotein alcohol dehydrogenases: Structure, function, and physiology. Arch. Biochem. Biophys. 428:10-21.

Vangnai, A. S., and Arp, D. J. 2001. An inducible 1-butanol dehydrogenase, a quinohaemoprotein, is involved in the oxidation of butane by "Pseudomonas butanovora". Microbiology 147:745-756.

Yanisch-Perron, C., Vieira, J., and Messing, J. 1985. Improved M13 phage cloning vectors and host strains: Nucleotide sequences of the M13mp18 and pUC19 vectors. Gene 33:103-119. 